\title{
Diagnóstico y plan de gestión de manejo ambiental mina didáctica del SENA
}

Facultad - Área de Ingeniería

\section{Diagnosis and management plan for teachers of environmental management sena minefaculty - engineering area}

\section{Resumen}

Con el fin de dar cumplimiento a la Legislación existente en Colombia en materia ambiental, se hace necesario implementar planes, programas, políticas, para generar una cultura ambiental, adecuada a las necesidades reales al área de explotación del Centro Nacional Minero CNM, Mina Didáctica del SENA, donde se efectuó un diagnóstico de las condiciones ambientales actuales, y se tomaron medidas que generan el mejoramiento de las circunstancias del desarrollo de la actividad minero ambiental y educativa, desarrollada por el CNM del SENA.

Palabras claves: Mina, diagnostico, Centro Nacional Minero, explotación, mejoramiento, SENA.

\section{Abstract:}

In order to comply with existing legislation on environmental matters in Colombia, it is necessary to implement plans, programs, policies, and create an environmental culture, appropriate to the real needs in the area of operation of the National Mining CNM, Mina Didactics SENA, a diagnosis was made of the current environmental conditions, for which decisions were made and actions that generate improvements in the circumstances of the development of the mining and educational environment, developed by CNM SENA.

Keywords: Mine, diagnosis, National Mining exploitation, improvement, SENA.

\section{Introducción}

El CNM es una institución de formación del Servicio Nacional de Aprendizaje SENA, inició labores respuesta a la necesidad de capacitación en el ramo minero, especialmente en Antioquia, Valle, Boyacá y Cundinamarca.
A raíz de la afectación sobre la Quebrada de las Torres y en general el entorno por parte del laboreo minero desarrollado en el Centro Nacional Minero CNM, Mina Didáctica del SENA, nace la idea de verificar las condiciones actuales y sus impactos generados, ya sean positivos o negativos, teniendo en cuenta que es una mina que represen-

*Escuela de posgrados Facultad Seccional Sogamoso UPTC- posgrados.sogamoso@uptc.edu.co * 
ta el ejemplo de la generación de prácticas minero ambientales.

Luego se procede a identificar los diferentes procesos y etapas para el desarrollo de la minería de carbón y la actividad educativa en la mina didáctica del CNM del SENA, para visualizar en que momentos del desarrollo se generaban emisiones, generación de residuos o efectos contaminantes, logrando bases importantes para la tabulación de información en las matrices manejadas por el equipo de trabajo.

\section{Antecedentes}

El CNM es una institución de formación del Servicio Nacional de Aprendizaje SENA, creado mediante decreto 126 del 23 de noviembre de 1970 emanado del consejo Directivo Nacional del SENA. Inicio labores el 23 de febrero de 1971 en respuesta a la necesidad de capacitación en el ramo minero, especialmente en Antioquia, valle, Boyacá y Cundinamarca

El Centro Nacional Minero consiente desde su creación, de la necesidad de formar de formar nuevos trabajadores y técnicos mineros, obedeciendo al diseño técnico, para minería cuenta con recursos para su formación integral como aulas, talleres, laboratorios, equipos, herramientas, sitios adecuados para las practicas, servicios básicos generales, normas y procedimientos que dan la oportunidad de que el aprendizaje sea hecho en forma racional.

\section{Metodología}

> Planeación y antecedentes de la operación del CNM SENA

$>$ Reconocimiento general de la zona y de las actividades de operación de la mina didáctica del CNM SENA.

Definición general de las actividades a desarrollar con base en la formulación de objetivos y alcances del trabajo practico.
Recopilación de información sobre el medio natural y las características técnica y operativa de la mina didáctica del SENA

$>$ Recopilación y selección de la información secundaria, es decir localización, geología, entre otras.

> Selección, adquisición de información y documentos.

$>$ Descripción técnica y operativa general de la mina didáctica del SENA.

$>$ Identificación de los tipos de impactos que genera la presencia y actividad de la mina didáctica del SENA.

$>$ Recomendaciones y fichas de manejo para mitigar las presiones ambientales.

\section{Diagnóstico}

1.1 Figura 1. Plano de labores

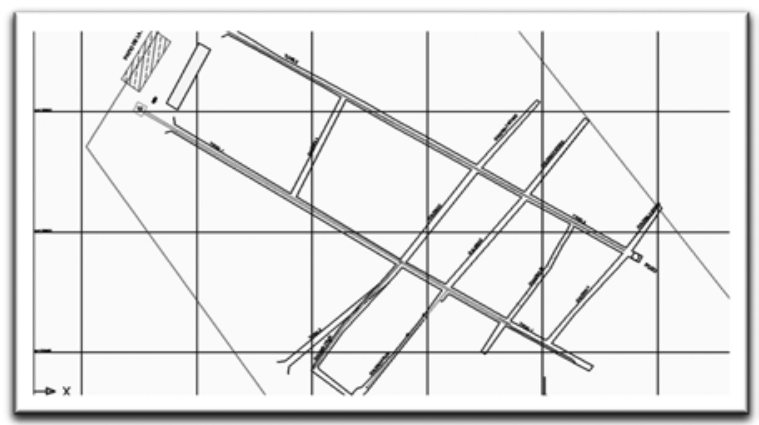

Fuente. Autores

A continuación se describen las labores con las que cuenta la mina didáctica.

- Túnel No 1. Localizado en las coordenadas Planas Gauss N 1.125.554; E 1.130.938, altura 2695 m.s.n.m. tiene una longitud de $210 \mathrm{~m}$, con una inclinación de $9^{\circ}$, tiene un sostenimiento inicial de $10 \mathrm{~m}$ en arcos de acero y concreto, continua con diferentes tipos de sostenimiento como arcos de acero de tres y cuatro secciones

- Túnel No 2. Localizado en las coordenadas Planas Gauss N 1.125.554; E 1.130.961, altura de 2694 m.s.n.m, tiene una inclinación 
de $9^{\circ}$, tiene un sostenimiento inicial de 10 $\mathrm{m}$ en arcos de acero y concreto, continua con diferentes tipos de sostenimiento como arcos de acero de tres y cuatro secciones.

- Túnel No 3. . Localizado en las coordenadas Planas Gauss N 1.125.442; E 1.130.985, altura de 2747 m.s.n.m, tiene una inclinación de $35^{\circ}$, tiene un sostenimiento inicial de $10 \mathrm{~m}$ en arcos de acero y concreto, continua con diferentes tipos de sostenimiento como arcos de acero de tres y cuatro secciones.

- Cinco galerías. Llamadas galería 1, galería 2 sur, galería 2 norte, galería 3 sur, galería 3 norte, galería 33 y galería 4 norte; todas las galerías tienen longitudes que varían entre 45 y $50 \mathrm{~m}$; su sostenimiento es en puerta alemana.

- Tambor. Une la galería 3 sur con la galería 2 norte, tiene una longitud de $23 \mathrm{~m}$, su sostenimiento es en cuadros de madera.

\subsection{MAQUINARIA Y EQUIPOS}

Dentro de los equipos se encuentra lo siguiente:

- Banda transportadora de $156 \mathrm{~m}$ de largo y $0.6 \mathrm{~m}$ de ancho

- Monorriel que alimenta la banda

- Tres ventiladores uno principal y dos auxiliares

- Compresores

- Pulmón

- Tolva metálica

- Malacate eléctrico

En el reconocimiento se observo que el cuarto de compresores no cuenta con trampas de grasas y aceites de los equipos, por lo tanto estos residuos caen directamente al piso, lo que genera un conflicto ambiental, los combustibles como gasolina y ACPM se encuentran en este mismo lugar, no existe señalización y adicionalmente los residuos solidos no cuentan con canecas para ser debidamente depositados.

\subsection{DESAGUE}

Para el desagüe, la mina cuenta con un pozo de bombeo ubicado al final del túnel 2 , este pozo tiene un área de $50 \mathrm{~m}^{2}$.
Existen 2 electrobombas, una de 15 hp y otra de 18hp.

\subsubsection{Tratamiento de aguas}

$\mathrm{Su}$ forma de tratamiento es mediante una torre de aireación (ver figura) cuya función principal es agregar oxigeno disuelto y capturar partículas en suspensión, su estructura es la siguiente: Primera flauta con caliza, segunda flauta con caliza, tercera flauta con coque, cuarta flauta con caliza y quinta flauta: con carbón activado

La caliza se utiliza para ajustar el $\mathrm{PH}$ y remover impurezas, mientras que el carbón activado debido a su alto grado de porosidad y alta superficie interna permite la absorción de metales pesados.

Figura 2. Tratamiento de aireación

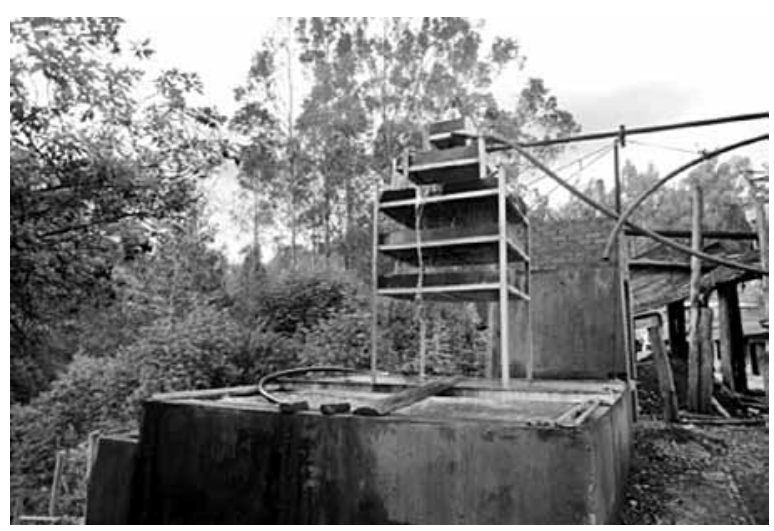

Fuente. Autores

Teniendo como base los estudios de aguas realizados por el CNM del SENA se encontró que el contenido de hierro de los efluentes mineros es de $123 \mathrm{ppm}$ teniendo como permisible $0.3 \mathrm{ppm}$ (Según lo establecido por la Resolución No 2115 de 2007, artículo 7 , Cuadro No 4), se observa la coloración del agua antes de ser tratada por medio de la torre de aireación, con un color naranja y luego de tratar las aguas y provenientes de la mina, estas no cambian su coloración; el PH del agua es de 3.5 luego de ser tratado por la torre de aireación y según la resolución debe estar entre 6,5 y 9 Estos índices de hierro y acidez no están cumpliendo con los parámetros ambientalmente exigidos y teniendo en cuenta que el agua después de haber sido tratada por medio de la torre de aireación es evacuada a la quebrada Las Torres genera un impacto ambiental negativo a la misma (Ver figuras 7, 8 y 9). 
Actualmente se encuentran realizando una planta piloto de floculación la cual si muestra resultados positivos será puesta en marcha su estructura es la siguiente: 3 Flautas de caliza,1 Flauta de coque y 1 Cajón mezclador (por medio de un motor se agrega hidróxido de sodio y sulfato de aluminio), este cajón permite que se sedimenten los lodos y se neutralice el $\mathrm{PH}$, por medio de una tubería en la parte inferior se evacuan los lodos y por un tubo localizado en la parte de anterior sale el agua para ser vertida en la quebrada Las Torres.

Figuras 3 y 4 . Planta de floculación

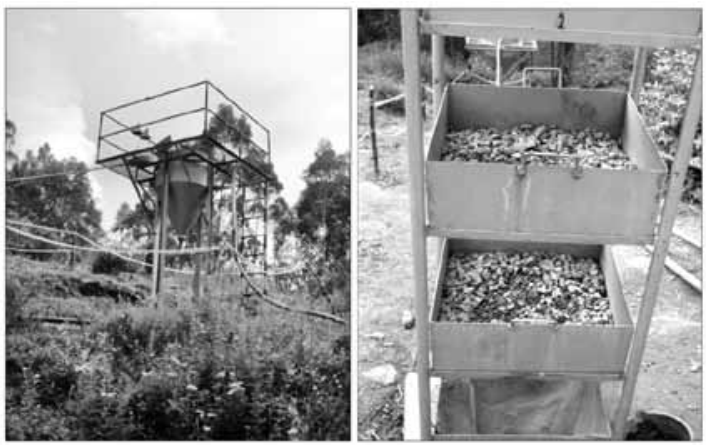

Fuente. Autores

\subsection{BOTADEROS}

La mina didáctica del Sena, cuenta con dos botaderos, uno hacia el norte y otro hacia el sur, el estéril que va hacia el norte, y el botadero sur esta temporalmente deshabilitado por problemas de deslizamientos.

En el reconocimiento de campo se observan deslizamientos del material estéril del botadero localizado al sur de las bocaminas, no se respeto la ronda de la quebrada de Las Torres que como mínimo de protección debe tener 15 metros a lado y lado de las orillas de la misma, según lo menciona POT de la ciudad de Sogamoso, siendo de urgencia la corrección, ya que el material estéril esta próximo a caer sobre la quebrada obstruyendo su cauce.

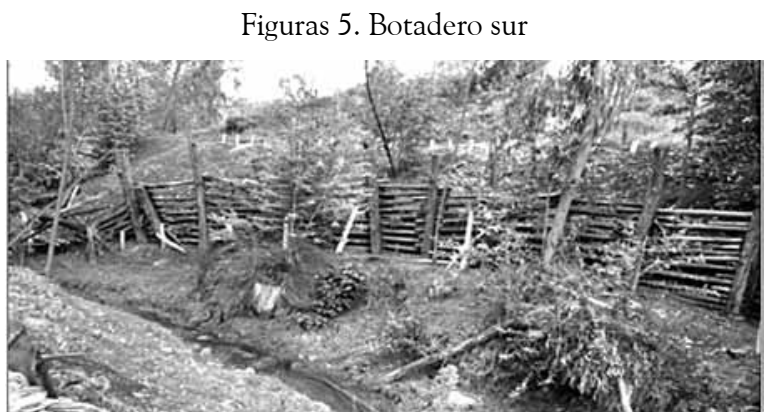

Fuente. Autores

\subsection{VENTILACION.}

La mina didáctica esta ventilada por dos sistemas de ventilación, el natural, y el mecanizado, el cual a su vez se divide en principal y auxiliar.

\subsection{ILUMINACION}

La mina se ilumina, con lámparas de seguridad contra explosiones de metano y otros gases ubicadas a los largo de Túnel 1 y Túnel 2, por las galerías y en los frentes de explotación.

\subsection{PATIO DE MADERAS}

Se cuenta con un patio de maderas señalizado y en correcto orden, esta techado evitando degradación de la madera; adicionalmente debido al descortezado que se realiza, este material se encuentra mezclado con residuos solidos como botellas y plásticos, el cual podría ser utilizado en el área del botadero como abono orgánico.

\section{MATRIZ DE FUERZAS MOTRICES Y DE BIENES Y SERVICIOS}

Para el desarrollo de la matriz de bienes y servicios se tomó como referencia (De Groot, 1992), entendiendo por funciones de los ecosistemas todos aquellos aspectos de la estructura y el funcionamiento de estos, con capacidad de generar servicios que satisfagan necesidades humanas de forma directa o indirecta; se define para el proyecto veintiuno (21) tipos de procesos y actividades asociados a la actividad minera del CNM del SENA agrupados en tres (3) categorías: Laboreo minero, Servicios de la mina y maquinaria y equipos (Ver Tabla 1).

Para la mina didáctica del SENA se evaluó el efecto al potencial natural y artificial de la zona como lo es la quebrada Las Torres, el bosque natural primario, bosque natural secundario, pasto natural, bosque plantado, cultivos agrícolas y herbáceas; sin dejar a un lado la parte social para lo cual se tuvo en cuenta la infraestructura rural.

Posteriormente se realizó una valoración cualitativa de la importancia que representa cada zona en alto, medio y bajo, señalándose a través de colores (Ver Tabla. 2), permitiendo así un análisis detallado de todas las funciones que posteriormente ayudaran a determinar cual de estas tiene mayor influencia en el ambiente. 
TABLA 2. Rango de calificación de importancia de las zonas con respecto a las funciones definidas por Groot y grupo de trabajo.

\begin{tabular}{|c|c|c|c|c|c|c|c|c|c|c|}
\hline $\begin{array}{c}\text { No aplica } \\
/ \text { No } \\
\text { presta } \\
\text { servicio } \\
\text { ambiental }\end{array}$ & $\mathrm{x}$ & $76 \%$ & $76 \%$ & $76 \%$ & $76 \%$ & $71 \%$ & $86 \%$ & $76 \%$ & $81 \%$ & $76 \%$ \\
\hline $\begin{array}{c}\text { Bajo } \\
\text { Servicio } \\
\text { ambiental }\end{array}$ & $\mathrm{x}$ & $10 \%$ & $14 \%$ & $14 \%$ & $14 \%$ & $10 \%$ & $5 \%$ & $10 \%$ & $14 \%$ & $5 \%$ \\
\hline $\begin{array}{c}\text { Medio } \\
\text { Servicio } \\
\text { ambiental }\end{array}$ & $\mathrm{x}$ & $5 \%$ & $5 \%$ & $5 \%$ & $5 \%$ & $10 \%$ & $5 \%$ & $10 \%$ & $5 \%$ & $0 \%$ \\
\hline $\begin{array}{c}\text { Alto } \\
\text { Servicio } \\
\text { ambiental }\end{array}$ & $\mathrm{x}$ & $\mathbf{1 0} \%$ & $\mathbf{5 \%}$ & $\mathbf{5 \%}$ & $5 \%$ & $10 \%$ & $\mathbf{5 \%}$ & $5 \%$ & $0 \%$ & $19 \%$ \\
\hline
\end{tabular}

A continuación mediante la gráfica No 1, se observa que a pesar de que la mina es un centro educativo minero ambiental, no se están ejecutando correctamente las prácticas ambientales que se están enseñando, como se estableció anteriormente en el diagnóstico, todos los impactos que genera las actividades propias del laboreo minero además de la maquinaria y equipos, es relevante que un centro de educación no realice las prácticas ambientales que infunde.

Gráfica 1. Servicio ambiental

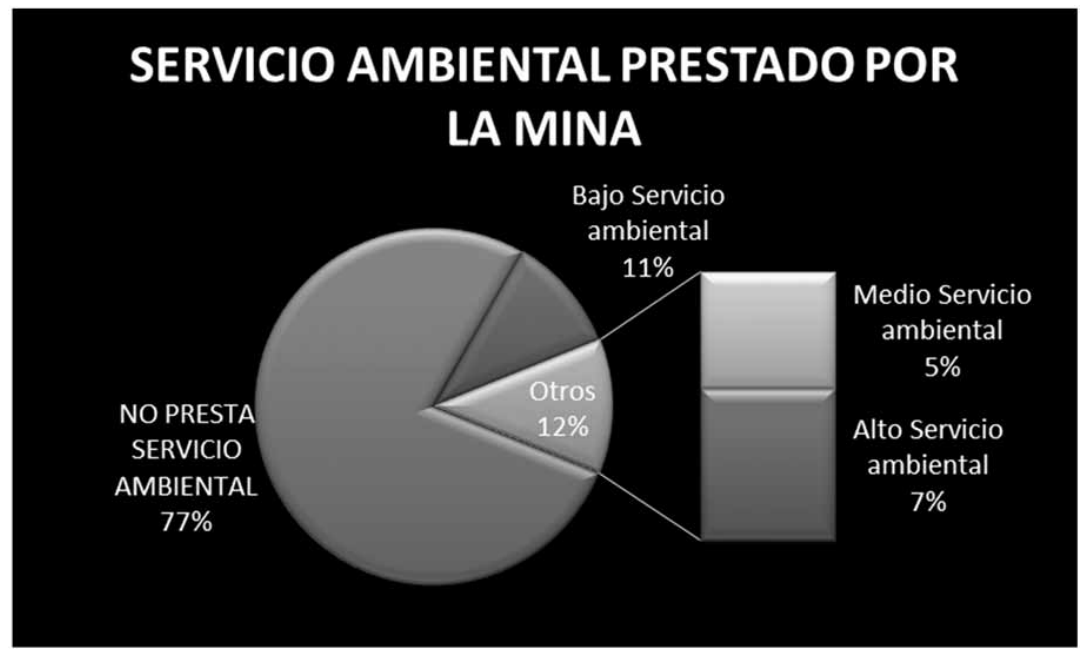

Fuente. Autores 


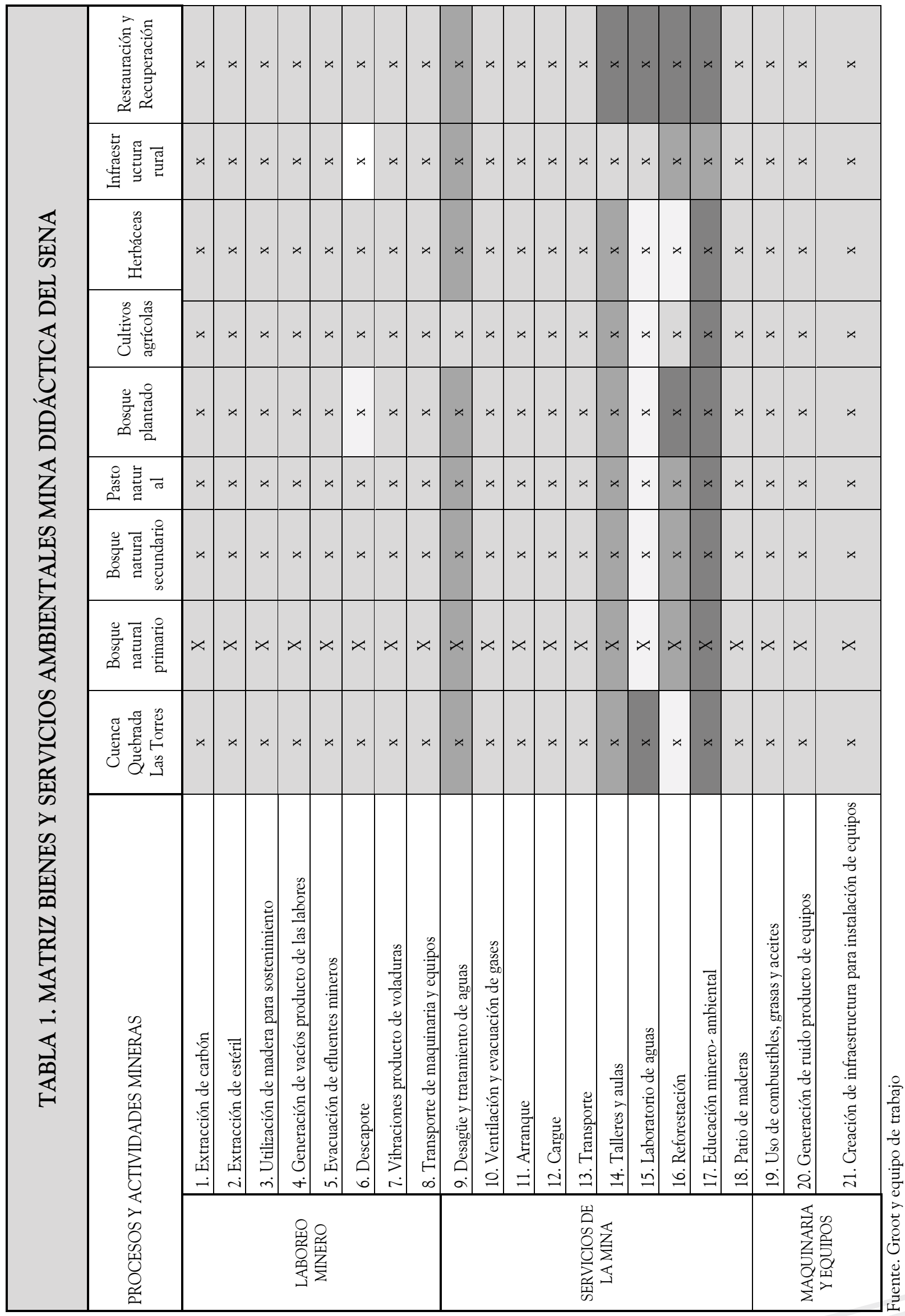




\section{Resultados}

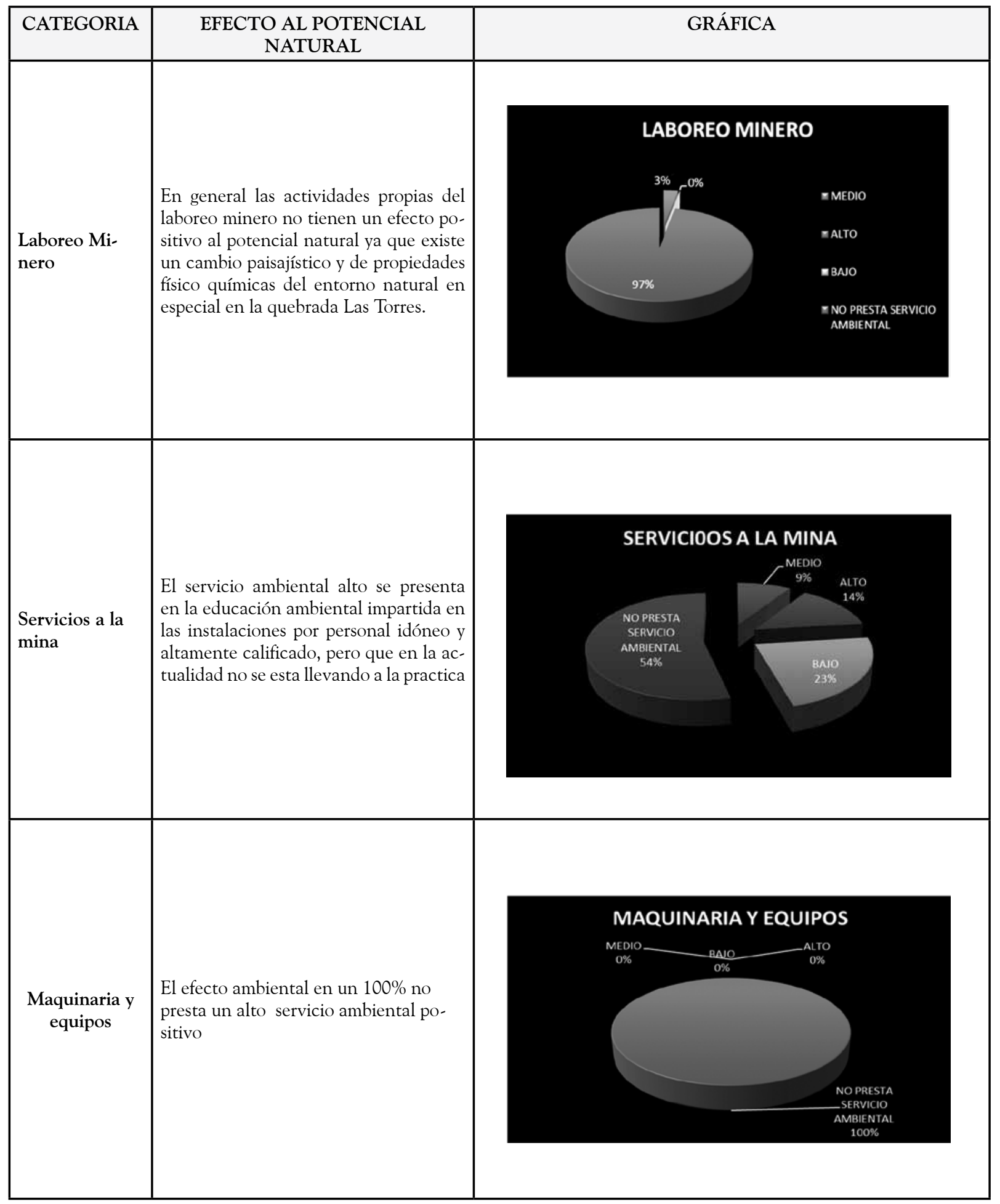

Fuente. Autores 


\section{FUERZAS MOTRICES Y PROPUESTAS PARA MITIGARLO}

A raíz de los resultados obtenidos anteriormente presentados, se realizó una matriz en la que se especifica cuales son las fuerzas motrices y propuestas para mitigarlos de forma general, si se requiere de las fichas completas remítase al trabajo de grado de la especialización en Gestión Ambiental del año 2012 titulado DIAGNÓSTICO Y PLAN DE GESTIÓN DE MANEJO AMBIENTAL MINA DIDÁCTICA DEL SENA, autores Ana María Monguí Galvis, Edwin Alexander Puentes Balaguera y Román Hernando Ortega Hernández.

\begin{tabular}{|c|c|c|c|c|}
\hline \multicolumn{5}{|c|}{ TABLA 2 Matriz de fuerzas motrices - modelo PER (Presión, Estado, Respuesta) MINA DIDÁCTICA DEL SENA } \\
\hline \multicolumn{2}{|c|}{ FUERZAS MOTRICES } & PRESIONES & IMPACTOS AMBIENTALES & $\begin{array}{l}\text { PROPUESTAS PARA MITIGARLO, } \\
\text { CORREGIRLO Y ELIMINARLO }\end{array}$ \\
\hline \multirow{7}{*}{ PRODUCCIÓN } & \multirow{7}{*}{ MINERÍA } & $\begin{array}{l}\text { 1. Generación de } \\
\text { residuos sólidos }\end{array}$ & $\begin{array}{l}\text { 1. Problemas de salud } \\
\text { 2. Disminución de biodiversidad } \\
\text { 3. Alteración del paisaje, con- } \\
\text { traste paisajístico }\end{array}$ & $\begin{array}{l}\text { 1. Recolección, clasificación y reciclaje de los } \\
\text { residuos sólidos por medio de canecas. } \\
\text { 2. Instalación de puntos verdes. } \\
\text { 3. Concientización de las formas de reutilización y } \\
\text { manejo de residuos mediante capacitaciones }\end{array}$ \\
\hline & & $\begin{array}{l}\text { 2. Vertimiento de } \\
\text { aguas ácidas }\end{array}$ & $\begin{array}{l}\text { 1. Disminución de la biota pre- } \\
\text { sente en la quebrada Las Torres } \\
\text { 2. Generación de erosión. } \\
\text { 3. Disminución en la biodiversi- } \\
\text { dad (plantas y animales). } \\
\text { 4. Ahuyentamiento de } \\
\text { animales por causa del } \\
\text { cambio en su hábitat. } \\
\text { 5. Contaminación en la quebra- } \\
\text { da Las Torres }\end{array}$ & $\begin{array}{l}\text { 1. Construcción de planta de tratamiento de aguas } \\
\text { optimo y eficiente en este caso la planta de flo- } \\
\text { culación que se encuentra como proyecto piloto. } \\
\text { 2. Reforestación alrede- } \\
\text { dor del área de tratamiento. } \\
\text { 3. Control y monitoreo de calidad del agua. }\end{array}$ \\
\hline & & $\begin{array}{l}\text { 3. Disposición de } \\
\text { estériles }\end{array}$ & $\begin{array}{l}\text { 1. Cambio paisajístico } \\
\text { 2. Deslizamientos de estériles } \\
\text { en la quebrada Las Torres. } \\
\text { 3. Invasión de área de inunda- } \\
\text { ción de la quebrada. } \\
\text { 4. Alteración de hábitats. } \\
\text { 5. Posible obstrucción del cauce } \\
\text { de la quebrada Las Torres }\end{array}$ & $\begin{array}{l}\text { 1. Diseño de un nuevo botadero para reubicación } \\
\text { de estériles del botadero sur. } \\
\text { 2. Construcción de drenajes y disipadores de } \\
\text { velocidad, para el correcto vertimiento de las } \\
\text { aguas lluvias. } \\
\text { 3. Reforestación del botadero norte para darle } \\
\text { estabilidad de los taludes. }\end{array}$ \\
\hline & & $\begin{array}{l}\text { 4. Deforestación } \\
\text { para usos de soste- } \\
\text { nimiento }\end{array}$ & $\begin{array}{l}\text { 1. Aumento de } \\
\text { erosión en el suelo. } \\
\text { 2. Perdida de absorción del agua } \\
\text { 3. Perdida del hábitat } \\
\text { de fauna y flora nativa } \\
\text { 4. Contaminación eólica } \\
\text { 5. Desestabilización de taludes }\end{array}$ & $\begin{array}{l}\text { 1. Reforestar con plantas nativas. } \\
\text { 2. Creación de vivero } \\
\text { 3. Plantar especies productoras de semillas que } \\
\text { atraigan aves y roedores. }\end{array}$ \\
\hline & & $\begin{array}{l}\text { 5. Generación de } \\
\text { subsidencia }\end{array}$ & $\begin{array}{l}\text { 1. Deslizamientos y reptación del } \\
\text { suelo. } \\
\text { 2. Desestabilización de infraes- } \\
\text { tructura rural } \\
\text { 3. Efecto visual negativo } \\
\text { 4. Cambio de propiedades de } \\
\text { agua subterránea }\end{array}$ & $\begin{array}{l}\text { 1. Mantenimiento del sostenimiento de la mina. } \\
\text { 2. Implementación de relleno a las labores } \\
\text { abandonadas. } \\
\text { Considerar los derrumbes dirigidos como técnica } \\
\text { de prevención de la subsidencia potencial a largo } \\
\text { plazo }\end{array}$ \\
\hline & & $\begin{array}{l}\text { 6. Generación de } \\
\text { ruido }\end{array}$ & $\begin{array}{l}\text { 1. Desplazamiento de especies } \\
\text { 2. Problemas de salud. }\end{array}$ & $\begin{array}{l}\text { 1. Construcción de barreras protectores } \\
\text { que aíslen la población cercana, natura- } \\
\text { les como arborización y materiales estriles, } \\
\text { y artificiales como planchas en concreto. } \\
\text { 2. Mantenimiento preventivo de equipos, atacan- } \\
\text { do la fuente de ruido. }\end{array}$ \\
\hline & & $\begin{array}{l}\text { 7. Aumento de la } \\
\text { erosión }\end{array}$ & $\begin{array}{l}\text { 1. Pérdida de la fertilidad del suelo } \\
\text { 2. Cambio en el aspecto visual } \\
\text { del terreno } \\
\text { 3. Desprendimiento y remocio- } \\
\text { nes en masa. }\end{array}$ & $\begin{array}{l}\text { 1. Revegetalización con capa vegetal y plantas de } \\
\text { bajo porte nativas. } \\
\text { 2. Canalizar aguas de escorrentía y aguas lluvia. }\end{array}$ \\
\hline
\end{tabular}


TABLA 2 Matriz de fuerzas motrices - modelo PER (Presión, Estado, Respuesta) MINA DIDÁCTICA DEL SENA

\begin{tabular}{|c|c|c|c|c|c|c|}
\hline \multicolumn{7}{|c|}{ TABLA 2 Matriz de fuerzas motrices - modelo PER (Presión, Estado, Respuesta) MINA DIDÁCTICA DEL SENA } \\
\hline \multicolumn{2}{|c|}{ FUERZAS MOTRICES } & \multirow[t]{2}{*}{ PRESIONES } & & $\begin{array}{c}\text { IMPACTOS } \\
\text { AMBIENTALES }\end{array}$ & \multicolumn{2}{|c|}{$\begin{array}{l}\text { PROPUESTAS PARA MITIGARLO, } \\
\text { CORREGIRLO Y ELIMINARLO }\end{array}$} \\
\hline \multirow{5}{*}{ PRODUCCIÓN } & \multirow{5}{*}{ MINERÍA } & & & $\begin{array}{l}\text { 1. Desestabilización del } \\
\text { terreno. } \\
\text { 2. Pérdida del atractivo } \\
\text { natural. } \\
\text { 3. Polución del agua y } \\
\text { aire. } \\
\text { 4. Afectación a la flora } \\
\text { y fauna. } \\
\end{array}$ & \multicolumn{2}{|c|}{$\begin{array}{l}\text { 1. Crear barreras naturales para evitar el alto } \\
\text { contraste visual. } \\
\text { 2. Proyectar acciones de adecuación y manejo de } \\
\text { escombreras. } \\
\text { 3. Adecuación de los colores de las instalaciones } \\
\text { para no alterar el contraste del paisaje }\end{array}$} \\
\hline & & $\begin{array}{l}\text { 9. Vibraciones por } \\
\text { voladura y equipos }\end{array}$ & & $\begin{array}{l}\text { 1. Desestabilización del } \\
\text { terreno. } \\
\text { 2. Problemas de salud. } \\
\text { 3. Generación de gases. } \\
\text { 4. Perdida de tranqui- } \\
\text { lidad de población } \\
\text { aledaña. }\end{array}$ & \multicolumn{2}{|c|}{$\begin{array}{l}\text { 1. Diseñar una voladura adecuada } \\
\text { a las condiciones geológicas } \\
\text { para minimizar las vibraciones. } \\
\text { 2. Diseñar métodos para mitigar las } \\
\text { voladuras dentro de la mina como } \\
\text { barreras naturales o artificiales. } \\
\text { 3. Realizar las voladuras en horarios que } \\
\text { no afecten la tranquilidad poblacional. } \\
\text { 4. Mantener un mecanismo de comunicación para } \\
\text { informar a los pobladores de las detonaciones }\end{array}$} \\
\hline & & $\begin{array}{l}\text { 10. Residuos de } \\
\text { grasas y aceites }\end{array}$ & & $\begin{array}{l}\text { 1. Contaminación de } \\
\text { quebrada Las Torres por } \\
\text { escorrentía. } \\
\text { 2. Perdida de fertilidad } \\
\text { del suelo } \\
\text { 3. Erosión del suelo. }\end{array}$ & \multicolumn{2}{|c|}{$\begin{array}{l}\text { 1. Construir trampas de grasas en concreto para } \\
\text { los equipos. } \\
\text { 2. Realizar u correcto almacenamiento de los } \\
\text { combustibles } \\
\text { 3. el aceite usado deberá recogerse y devolverse a } \\
\text { los proveedores. } \\
\text { 4. No dejar sobrantes en el sitio de trabajo, o en } \\
\text { zonas verdes. }\end{array}$} \\
\hline & & $\begin{array}{l}\text { 11. Generación de } \\
\text { material particulado }\end{array}$ & & $\begin{array}{l}\text { 1. Problemas de salud } \\
\text { 2. Acidificación de suelos } \\
\text { y fuentes hídricas }\end{array}$ & \multicolumn{2}{|c|}{$\begin{array}{l}\text { 1. Instalación de barreras naturales o artificiales } \\
\text { rompe vientos } \\
\text { 2. Humectación por medio de aspersores } \\
\text { de botaderos y tolva de carbón. } \\
\text { 3. Mantenimiento continuo de las vías }\end{array}$} \\
\hline & & 12. Emisión de gases & & $\begin{array}{l}\text { 1. Problemas de salud. } \\
\text { 2. Disminución de la } \\
\text { capa de ozono. } \\
\text { 3. Calentamiento global. } \\
\end{array}$ & \multicolumn{2}{|c|}{$\begin{array}{l}\text { 1. Mantenimiento preventivo de equipos } \\
\text { 2. Implementación de nuevas tecnologías para las } \\
\text { voladuras }\end{array}$} \\
\hline \multirow{3}{*}{ CONSUMO } & \multirow{3}{*}{\multicolumn{2}{|c|}{ POBLACIÓN }} & \multirow{3}{*}{$\begin{array}{l}\text { EDUCA- } \\
\text { CIÓN }\end{array}$} & $\begin{array}{l}\text { 1. Generación de resi- } \\
\text { duos sólidos. }\end{array}$ & $\begin{array}{l}\text { 1. Problemas de salud } \\
\text { 2. Disminución de } \\
\text { biodiversidad } \\
\text { 3. Alteración del } \\
\text { paisaje, contraste } \\
\text { paisajístico }\end{array}$ & \begin{tabular}{|l} 
1. Recolección, cla- \\
sificación y reciclaje \\
de los residuos sólidos \\
por medio de canecas. \\
2. Instalación de \\
puntos verdes. \\
3. Concientización de las \\
formas de reutilización y \\
manejo de residuos me- \\
diante capacitaciones \\
\end{tabular} \\
\hline & & & & 2. Generación de ruido. & $\begin{array}{l}\text { 1. Desplazamien- } \\
\text { to de especies } \\
\text { 2. Problemas de salud. }\end{array}$ & $\begin{array}{l}\text { 1. Construcción de barre- } \\
\text { ras protectores que aílen } \\
\text { la población cercana, } \\
\text { naturales como arboriza- } \\
\text { ción y materiales esté- } \\
\text { riles, y artificiales como } \\
\text { planchas en concreto. } \\
\text { 2. Mantenimiento } \\
\text { preventivo de equipos, } \\
\text { atacando la fuente de } \\
\text { ruido. } \\
\end{array}$ \\
\hline & & & & $\begin{array}{l}\text { 3. Aumento de la } \\
\text { densidad poblacional }\end{array}$ & $\begin{array}{l}\text { 1. Generación de resi- } \\
\text { duos sólidos y líquidos. } \\
\text { 3. Generación de } \\
\text { ruido } \\
\text { 4. Disminución de } \\
\text { la biodiversidad. } \\
\text { 5. Contaminación de } \\
\text { la quebrada Las Torres }\end{array}$ & $\begin{array}{l}\text { 1. Concientización y } \\
\text { capacitación de buenas } \\
\text { prácticas ambientales. }\end{array}$ \\
\hline
\end{tabular}




\section{Conclusiones}

La mina presenta serias deficiencias ambientales debido a las presiones ejercidas por: la ineficiencia del tratamiento de aguas, la localización del botadero, manejo de residuos sólidos, falta de reforestación con especies nativas.

$>$ El tratamiento de aguas actual es ineficiente por falta de mantenimiento, y optimización de la estructura presente.

$>$ De acuerdo a los análisis de PH y concentración de hierro presente en el agua tratada, por la torre de aireación, no cumple con los estándares de calidad que comprende el artículo 7, cuadro No 4 de la Resolución No 2115 de 2007 establecido por el Ministerio de la Protección Social, Ministerio de Ambiente, Vivienda y Desarrollo Territorial, por medio de la cual se señalan características, instrumentos básicos y frecuencias del sistema de control y vigilancia por la calidad del agua para consumo humano.

$>$ El botadero se localiza cerca a la quebrada Las Torres, donde no se cumple la ronda establecida por el POT de la ciudad de Sogamoso, es decir de $15 \mathrm{~m}$ a lado y lado, el cual debe reubicarse teniendo en cuenta que se está generando caída de este material a la quebrada Las Torres y una posible obstaculización de su cauce.

$>$ No se realizó reforestación en los botaderos norte y sur, por ende el impacto visual y paisajístico generado es alto.

$>$ Se debe aplicar un manejo de residuos sólidos, en donde se puede reciclar el material que se encuentra cerca de la bocamina.

$>$ A pesar de que en el CNM SENA su servicio está enfocado en la educación minero ambiental esta ultima no se ve reflejada en la práctica.

Se deben aplicar trampas de grasas en los lugares en donde se localicen equipos que utilicen aceites.

\section{Bibliografía}

Resolución 2112 del 22 de julio de 2007

Acuerdo No 096 de 2000 por el cual se adopta el plan de ordenamiento territorial del municipio de Sogamoso - Boyacá. 